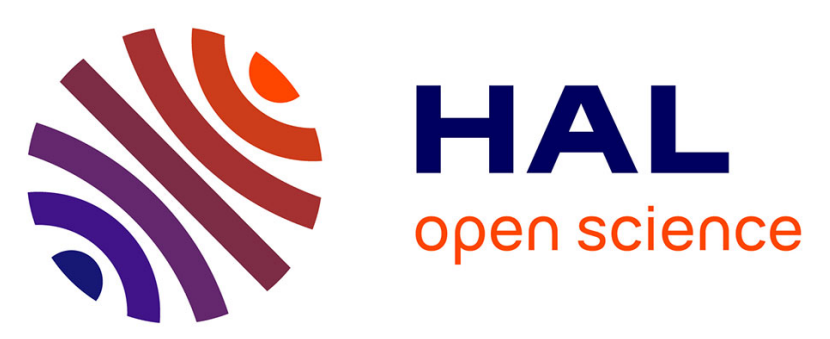

\title{
Orthogonal micro-cutting modeling of the Ti17 titanium alloy using the crystal plasticity theory
}

\author{
Yessine Ayed, Camille Robert, Guénaël Germain, Amine Ammar
}

\section{To cite this version:}

Yessine Ayed, Camille Robert, Guénaël Germain, Amine Ammar. Orthogonal micro-cutting modeling of the Ti17 titanium alloy using the crystal plasticity theory. Finite Elements in Analysis and Design, 2017, 137, pp.43-55. 10.1016/j.finel.2017.08.002 . hal-02283179

\section{HAL Id: hal-02283179 \\ https://hal.science/hal-02283179}

Submitted on 10 Sep 2019

HAL is a multi-disciplinary open access archive for the deposit and dissemination of scientific research documents, whether they are published or not. The documents may come from teaching and research institutions in France or abroad, or from public or private research centers.
L'archive ouverte pluridisciplinaire HAL, est destinée au dépôt et à la diffusion de documents scientifiques de niveau recherche, publiés ou non, émanant des établissements d'enseignement et de recherche français ou étrangers, des laboratoires publics ou privés. 


\title{
Orthogonal micro-cutting modeling of the Ti17 titanium alloy using the crystal plasticity theory
}

\author{
Y. Ayed *, C. Robert, G. Germain, A. Ammar \\ Arts et Métiers ParisTech, LAMPA,2 bd du Ronceray, 49035 Angers Cedex, France
}

$\begin{array}{lllllllllllllllll}\text { A } & B & S & T & R & A & C & T\end{array}$

Keywords:

Titanium alloys

Crystal plasticity

Micro-cutting

Finite strain

Finite elements

Chip formation
The development of computation means has allowed the simulation of complex mechanical problems. The first simulations of manufacturing processes at the microstructure scale, namely in the field of machining, have recently emerged. In this study, and on the basis of previous research, a novel approach to machining simulation is proposed. A crystal plasticity behavior law has thus been implemented and its parameters have been identified, for each of the two phases constituting the material. This is achieved through experimental tests conducted under extreme conditions of temperature and strain rates. Numerical models are composed of grains in the form of Voronoï cells. Random crystal orientations have also been assigned to each grain. This has subsequently allowed the simulation of the machining process. Access to local physical parameters such as crystal orientations, their evolution and phase transition thus presents a major breakthrough in this field.

\section{Introduction}

Titanium alloys are widely used in the aeronautical, aerospace and biomedical fields thanks to their excellent strength-to-weight ratio, their good mechanical properties, even at high temperatures, and their corrosion resistance. Despite these characteristics, titanium alloys are difficult-to-cut materials, and their poor machinability presents a challenging problem $[1,2]$. In order to deal with this issue, it is indispensable to investigate the different phenomena interacting during machining. Nowadays, using the best experimental means (infrared thermography, high speed camera, Digital Image Correlation, etc.), it is still impossible to access the cutting zone. Thus, numerical simulation of the cutting process provides additional information [3-6]. However, this modeling is hampered by the complexity of the process and the strong interaction of different complex physical phenomena in too short a time lapse and in a very small area. Indeed, as reported by Garcia-Gonzalez et al. [7], the cutting temperature measured by different experimental means such as infrared thermography varies from $700^{\circ} \mathrm{C}$ to up to $1000^{\circ} \mathrm{C}$ (depending on cutting conditions). Temperature levels estimated by numerical simulations are in the same range of the experimental ones $[8,9]$. The machined surface undergoes large deformations and complex thermal cycles. As reported by Outeiro et al. [10], plastic deformation levels are very high and vary from 1.8 to 3.4 (OFHC copper). If we add to all these issues the integration of the dynamic constitutive equations and friction, the task becomes even more complex. For all these reasons, the modeling of machining is particularly dependent on the scientific evolutions of experimental, numerical and computational means.

Over the last two decades, the numerical simulation of machining has witnessed significant advances. Most previous cutting models use the phenomenological behavior law of Johnson-Cook (JC) [11] which has allowed researchers to closely study some physical phenomena during the chip formation process. Nevertheless, it is important to point out that this type of modeling does not provide enough information at the local level; at this scale, as a matter of fact, microstructure characteristics (especially grain size and phase transformation) impacts material behavior.

With increasingly complex and quickly evolving computing means, recent years have seen further progress in this area as more complex models have been proposed. The studies conducted by Simoneau et al. [12-14] led to the development of a cutting model which takes account of material phases. It should be noted that the behavior of each phase is modelled by the JC constitutive law. This has allowed for more accurate simulations at the levels of chip formation, temperature fields and cutting forces. The same procedure was used by Obikawa et al. [15] by modeling the ferrite and pearlite with two different material

\footnotetext{
* Corresponding author.

E-mail address: yessine.ayed@ensam.eu (Y. Ayed).
} 


\begin{tabular}{|llll|}
\hline \multicolumn{2}{|c|}{ Nomenclature } & $f_{\varphi_{i}}$ & Phase fraction \\
$\alpha$ & Alpha phase & $\varepsilon_{\varphi_{i}}$ & Phase deformation \\
$\alpha$ & Deformation gradient tensor & $\beta$ & Beta phase \\
$R$ & Rigid rotation tensor & $f^{s}$ & Yield function \\
$U$ & Right stretch tensor & $\rho$ & Material density \\
$L$ & Velocity gradient tensor & $D^{T}$ & Macroscopic damage variable \\
$D$ & Strain rate tensor $d^{s}$ & $q$ & Internal state hardening variable \\
$N_{s}$ & Slip systems number & $d^{s}$ & Damage variable at the slip system level \\
$n_{0}^{s}$ & Slip plane normal & $\widetilde{X}$ & Effective variable \\
$m_{0}^{s}$ & Slip direction & $R^{s}$ & Internal state hardening variable \\
$\dot{\gamma}^{s}$ & Shear rate & $\mathcal{L}$ & Elasticity tensor \\
$W_{e}$ & Spin tensor & $H$ & Interaction matrix \\
$\nabla$ & Cauchy tensor rate & $Y^{s}$ & Damage force \\
$\sigma$ & Kirchhoff stress & $\Phi^{s}$ & Plastic potential \\
$\tau$ & Resolved shear stress & $\Phi_{d}^{s}$ & Damage part of the plastic potential \\
$\tau^{s}$ & Overall damage in the grain & $\dot{\lambda}^{s}$ & Viscoplastic multiplier \\
$D^{G}$ & & $Z(T)_{\alpha}$ & $\alpha$ phase rate \\
& & $V_{c}$ & Cutting speed \\
& & & \\
\hline
\end{tabular}

parameters. Mohammed et al. [16,17] developed a cutting model that takes into account the effect of the microstructure of compacted graphite iron on chip formation. Based on physical behavior laws, and in particular the mobile dislocation density theory, other recent research studies aimed to predict the grain refinement resulting from the phenomenon of dynamic recrystallization [18-20].

These researches have shown the need to use constitutive material behavior laws based on the theory of crystal plasticity in order to develop more realistic models. Indeed, the models based on crystal plasticity present many advantages, especially the ability to simulate and predict the evolution of the texture of a material under strong thermomechanical solicitation. The researches conducted by Peirce et al. [21] and Asaro et al. [22,23], and which were based on Schmidt's study [24], have paved the ground for the development of this research axis.

Other research work has focused on the simulation, at the microstructure scale, of processes such as deep drawing [25-27], ultrasonic consolidation [28], bending [29] and stamping [30]. The use of the crystal plasticity (CP) theory has permitted to have a physical insight into grain size effect, damage, texture effect and to have an accurate prediction of the forming limit diagrams (FLDs) at different temperature levels [31]. The modeling of multiphase materials has allowed for a better understanding of certain deformation and damage mechanisms. In the case of dual-phase steels, this type of modeling has given a better insight into failure mechanisms, shear localisation and the contribution of each phase [32-34]. In the case of titanium alloys, more realistic simulations have been carried out by taking into account the material behavior of the $\alpha$ and $\beta$ phases [35,36].

The modeling of the machining process using a polycrystalline model has recently emerged with the study conducted by Zhang et al. [37]. This model has the advantage of using the assumption of a 2D plane strain and then significantly reducing computation time. Kinematic and isotropic hardening have been implemented, assuming no rotation of crystal orientations. To take account of the damage at the intragranular scale, the authors have proposed a model based on the Lemaitre and Chaboche damage model. Intergranular fracture has been modeled by using cohesive elements at grain boundaries. The comparison between the numerical model and the experimental results for many cutting conditions seems to give good results. Meanwhile a combination of the finite element method and Smoothed Particle Hydrodynamics (SPH) was employed by Abolfaz et al. [38] in order to determine the influence of crystallographic orientations on the evolution of the cutting forces. A similar test was performed for the simulation of copper machining $[39,40]$. The study carried out by Tajalli et al. [40] showed that the initial grain orientation affects the morphology of the chip and the cutting forces. The recent study carried out by Li et al. [41] proves the capability of this kind of modeling for an accurate prediction of the deformed material texture.

These different studies have evidenced the pertinence of this approach and the need to reinforce current research in the field. The work proposed in this study is thus inscribed within this perspective of continuity. The material used in the present study, Ti17, has a millimetric grain size (Fig. 1). The Ti17 (Ti-5Al-2Sn-4Mo-2Zr-4Cr) is a beta-rich titanium alloy. As reported by R.R. Boyer [42], Ti17 has been developed by General Electric Aircraft Engines. Known for its deep hardenability and high fracture toughness, it can be used below $400^{\circ} \mathrm{C}$. As a case in point, it is actually used in some Compressor stages of the GE90 engine. The tensile strength of the material $\left(\sigma_{U T S}\right)$ is around $1110 \mathrm{MPa}$ and its elongation at break varies from $5 \%$ to $8 \%$.

It therefore seems interesting to explicitly model the microstructure to take into account crystal modifications which may occur during chip formation. The main objective of this study is to develop a model which allows for the machining simulation of the Ti17 using the crystal plasticity theory. This research has been carried out as follows:

- Model the gains with Voronoï cells;

- Model the $\beta$ phase with 12 slip systems (BCC structure) and the $\alpha$ phase with 24 slip systems (HCP structure) [43,37,44];

- Implement a crystal plasticity constitutive equation considering isotropic hardening and damage evolution;

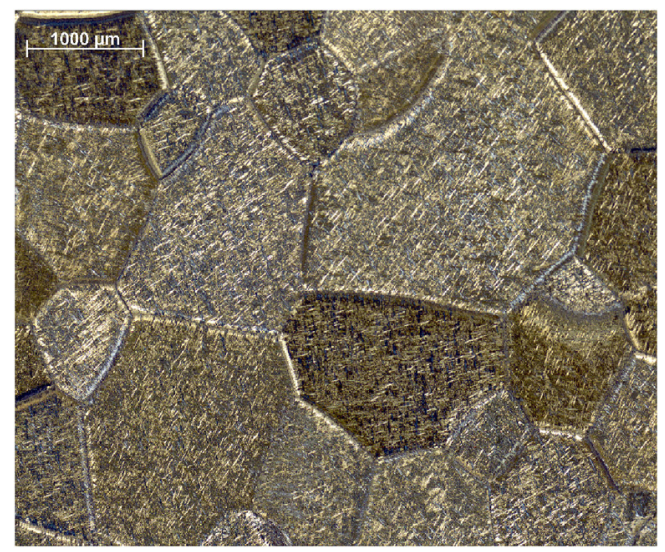

Fig. 1. As-delivered material microstructure. 
Table 1

Crystallographic slip systems.

\begin{tabular}{llc}
\hline \multicolumn{2}{l}{ Slip systems for the $\alpha$ phase } & \\
\hline Basal $<\mathrm{a}>$ & $\{0001\}[11 \overline{2} 0]$ & 3 \\
Prismatic $<\mathrm{a}>$ & $\{10 \overline{1} 0\}[11 \overline{2} 0]$ & 3 \\
Pyramidal $<\mathrm{a}>$ & $\{1 \overline{1} 01\}[11 \overline{2} 0]$ & 6 \\
Pyramidal $<\mathrm{c}+\mathrm{a}>$ & $\{\overline{1011}\}[11 \overline{2} 3]$ & 6 \\
\hline Slip systems for the $\beta$ phase & & 12 \\
\hline
\end{tabular}

- Take into account the rotation of the crystal lattice (finite transformations);

- Take into account phase transformation.

The list of the 36 slip systems is shown in Table 1. The disorientation between the HCP and the BCC systems has also been taken into account.

\section{Crystal plasticity modeling}

\subsection{Implementation of a crystal plasticity constitutive equation}

The numerical integration of crystal plasticity equations is often challenging. Indeed, the major two obstacles are the strong nonlinearity of these equations and the considerable computation time needed. Several algorithms with implicit [45-47] and explicit $[48,49]$ integration schemes have been set up. As reported by Rashid et al. [50] and Dumoulin et al. [48] the explicit integration scheme seems to be more suitable for highly non-linear problems. An interesting comparative study of the integration of crystal plasticity equations has been carried out by Harewood and McHugh [51]. The authors tested explicit and implicit (theta method) integration schemes using ABAQUS FEM solver. They demonstrated that the explicit integration scheme is more efficient in the case of large deformations, especially when there is contact between two or more solids.

In order to incorporate strain rate sensitivity, large deformations and damage evolution, the Boudifa constitutive behavior equation [25] has been used for this study. However, it has been modified to take thermal softening into account. Due to the extreme conditions of high strain rates, high temperatures, and tool/chip contact during chip formation, explicit integration has also been adopted.

\subsubsection{Kinematics}

In order to take into account the large deformations in the cutting process simulation, a finite deformation framework has been adopted. In this formulation, it is assumed that the crystalline lattice undergoes elastic deformations and rigid body rotations; the material flows through the crystal lattice and it is deformed plastically by the crystalline slip. Hence, to describe material motion, it is necessary to use two coordinate systems. The first is attached to the crystal lattice (rotates with the crystal lattice) and the second is attached to the material (rotates with the material). Hence, the deformation gradient tensor $F$ can be decomposed into two components: an elastic part $F^{e}$ which includes the elastic deformations and the rigid-body rotations, and an plastic part $F^{p}$, that describes the crystalline slip. Fig. 2 illustrates the decomposition of the deformation gradient tensor.

This decomposition of the deformation gradient tensor can be written as follows:

$F=F^{e} F^{p}, \quad F=R U$

$R$ is the rigid rotation tensor and $U$ is the right stretch tensor. The velocity gradient $L$ also consists of an elastic part $\left(L^{e}\right)$ and a plastic part $\left(L^{p}\right)$ :

$L=\dot{F} F^{-1}=L^{e}+L^{p}$
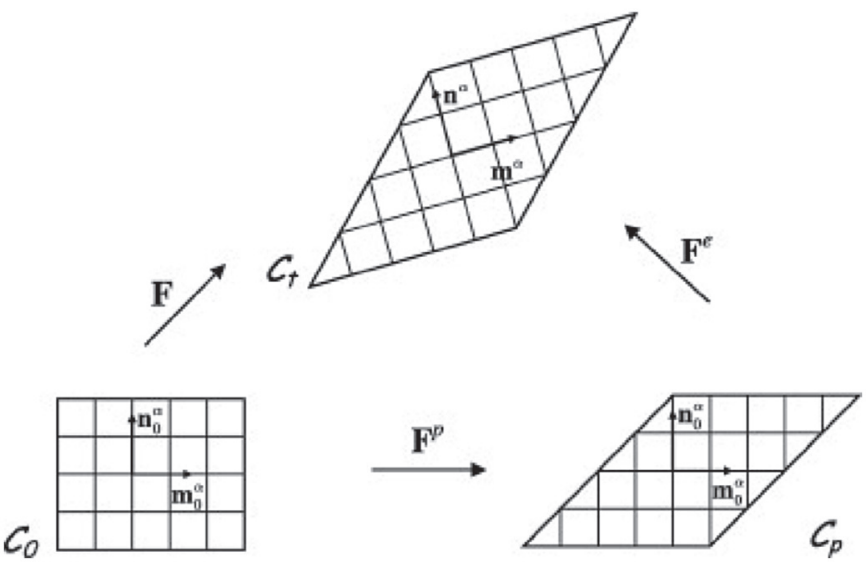

Fig. 2. Decomposition of the deformation gradient tensor ([48]).

$L^{p}=F^{e} \dot{F}^{p} F^{p-1} F^{e-1}=D+W$

$L=D_{e}+D_{p}+W_{e}+W_{p}$

$D_{e}$ and $D_{p}$ represent respectively the elastic and plastic strain rates. The rotation of the crystal lattice is represented by the elastic part of the spin tensor $W_{e}=\Omega=\dot{R} R^{T}$. Plastic deformation is assumed to be due to the slip within the crystalline lattice. Thus, the plastic part of the velocity gradient can be written as follows:

$L_{p}=\sum_{s=1}^{N_{s}} \dot{\gamma}^{s} n_{0}^{s} m_{0}^{s}$

$N_{s}$ is the number of slip systems while $n_{0}^{s}$ and $m_{0}^{s}$ represent, respectively, the normal to the slip plane (s) and the slip direction; $\dot{\gamma}^{s}$ is the shear rate.

The elastic part of the velocity gradient, then, becomes:

$L_{e}=L-L_{p}=\dot{F} F^{-1}-\sum_{s=1}^{N_{s}} \dot{\gamma}^{s} n_{0}^{s} m_{0}^{s}$

It is now possible to calculate the crystal orientations variation as:

$n^{s}=F^{e} n_{0}^{s}$

$m^{s}=m_{0}^{s} F^{e^{-1}}$

\subsubsection{Constitutive relations}

In the case of large deformations, FEM codes provide the GreenNagdhi and/or the Jauman rate to calculate stress change during deformation. The stress rate $\underset{\nabla *}{\sigma}$, which designates the corotational stress rate seen by a rotating observer with the crystal lattice, is given by equation (9).

$\stackrel{\nabla *}{\sigma}=\dot{\sigma}-W_{e} \sigma+\sigma W_{e}$

Indeed, the change rate of the Cauchy tensor $\sigma$ in the material corotational frame, according to $W$, can be expressed as:

$\stackrel{\nabla}{\sigma}=\dot{\sigma}-W \sigma+\sigma W$

Based on equations (9) and (10), the corotational stress on axes rotating with the material can be expressed as following:

$\stackrel{\nabla}{\sigma}=\stackrel{\nabla *}{\sigma}-\left(W-W_{e}\right) \sigma+\sigma\left(W-W_{e}\right)$

The Kirchhoff stress $\tau$ can be obtained from the Cauchy stress $\sigma$ using equation (12).

$\tau=\operatorname{det}(F) \sigma$

Thus, the resolved shear stress $\tau^{s}$ on the slip system $s$ is expressed as:

$\tau^{s}=n^{s} \tau m^{s}$ 


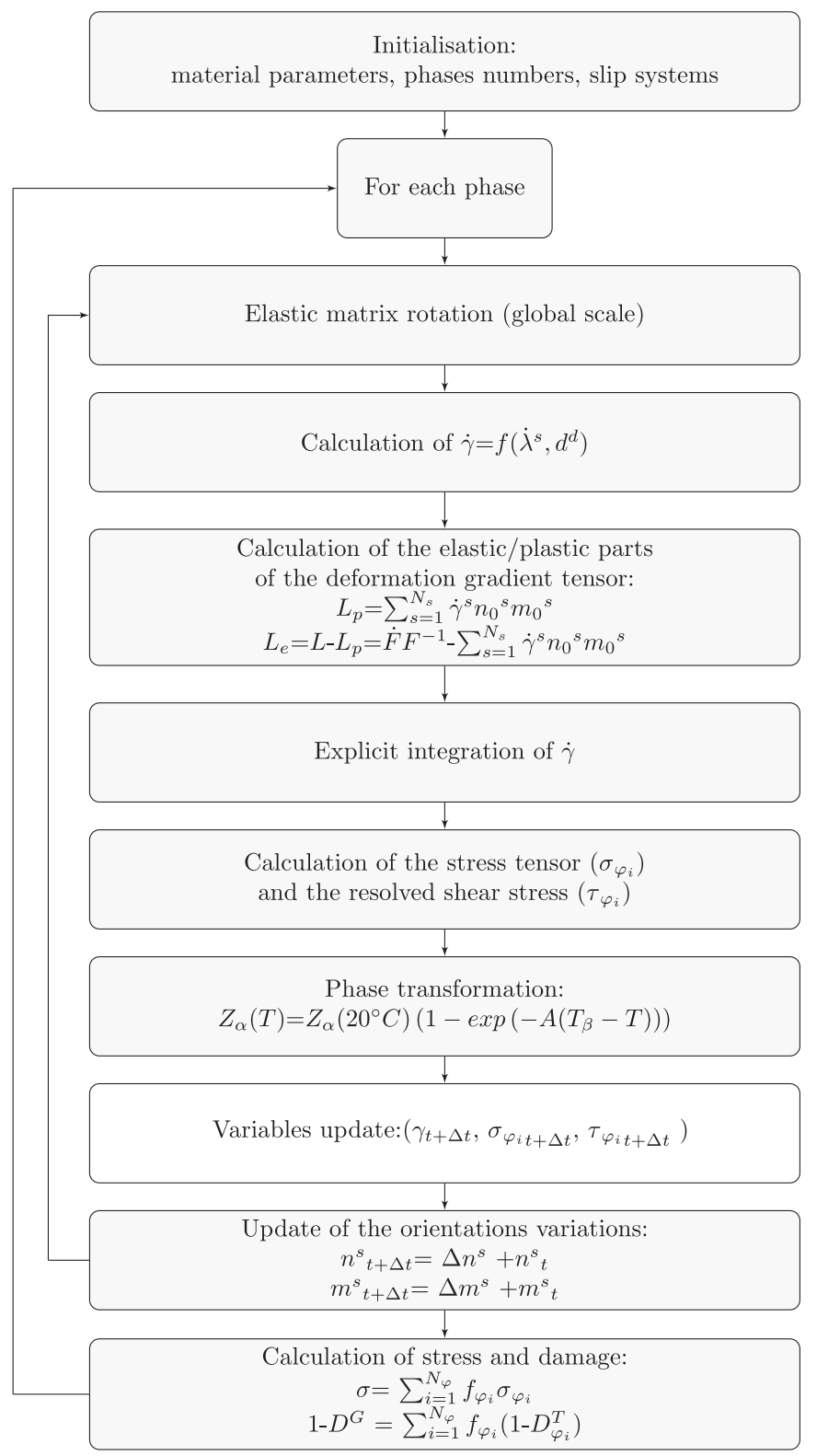

Fig. 3. Main calculation steps.

\subsubsection{The case of a multiphase material}

In the proposed model, it is assumed that total deformation is the same in different phases $\varphi_{i}$ :

$\varepsilon=\varepsilon_{\varphi_{i}}$

In this case, the stress tensor is the volume average of the stresses in each phase. The evolution of stresses can be calculated as follows:

$\sigma=\sum_{i=1}^{N_{\varphi}} f_{\varphi_{i}} \sigma_{\varphi_{i}}$

$\dot{\sigma}=\sum_{i=1}^{N_{\varphi}}\left(f_{\varphi_{i}} \dot{\sigma}_{\varphi_{i}}+\dot{f}_{\varphi_{i}} \sigma_{\varphi_{i}}\right)$

The fraction of each phase is represented by $f_{\varphi_{i}}$. Regarding the damage, a scalar variable $D^{G}$, which represents the overall damage in the grain, can be defined as follows:

$1-D^{G}=\sum_{i=1}^{N_{\varphi}} f_{\varphi_{i}}\left(1-D_{\varphi_{i}}^{T}\right)$

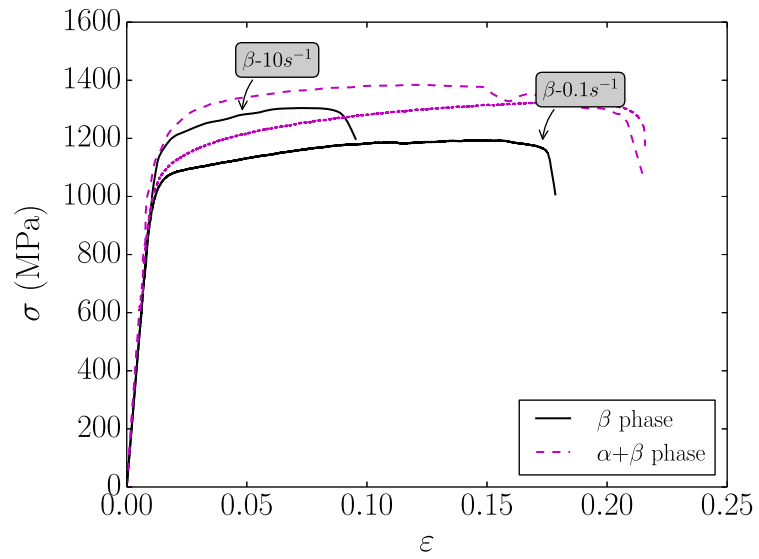

Fig. 4. Mechanical behavior of the $\beta$-treated Ti17 and the $\beta+\alpha$ Ti17 at different strain rates $\left(0.1 \mathrm{~s}^{-1}\right.$ and $10 \mathrm{~s}^{-1}$ at $\left.25^{\circ} \mathrm{C}\right)$.

\subsubsection{Energy relations}

As reported by Boudifa [25], the free energy is written according to an additive decomposition of an elastic part and inelastic part:

$\rho \psi\left(\varepsilon_{e}, q^{s}, d^{s}\right)=\rho \psi_{e}\left(\varepsilon_{e}, D^{T}\left(d^{s}\right)\right)+\rho \psi_{p}\left(q^{s}, d^{s}\right)$

where $\rho$ is the material density, $D^{T}$ is a macroscopic variable for measuring of the damage, $\varepsilon_{e}$ is the elastic deformation, $q$ is the internal variable of isotropic hardening and $d^{s}$ is the damage variable at the slip system level. In order to take into account the impact of damage evolution on the mechanical behavior of the material, effective state variables are used $\left(\widetilde{\varepsilon}_{e} ; \widetilde{\tau}\right)$.

$\tilde{\varepsilon}_{e}=\sqrt{1-D^{T}} \varepsilon_{e}$ and $\tilde{\tau}=\frac{\tau}{\sqrt{1-D^{T}}}$

At the level of the slip systems, the effective internal isotropic hardening variables $\left(\widetilde{q}^{s} ; \widetilde{R}^{s}\right)$ are written as follows:

$\widetilde{q}^{s}=\sqrt{1-d^{s}} q^{s} \quad$ and $\quad \widetilde{R}^{s}=\frac{R^{s}}{\sqrt{1-d^{s}}}$

The elastic and the plastic parts of the free energy are presented, respectively, by equations (21) and (27). Where $\mathcal{L}$ is the elasticity tensor, $Q$ is a parameter and $H$ is a matrix which represents the interactions between the different slip systems.

$\rho \psi_{e}\left(\varepsilon_{e}, D^{T}\left(d^{s}\right)\right)=\left(1-D^{T}\right) \frac{1}{2} \mathcal{L} \varepsilon_{e}: \varepsilon_{e}$

$\rho \psi_{p}\left(q^{s}, d^{s}\right)=\frac{Q}{2} \sum_{s=1}^{N_{s}} \sum_{r=1}^{N_{s}} H^{r s} \widetilde{q}^{s} \widetilde{q}^{r}$

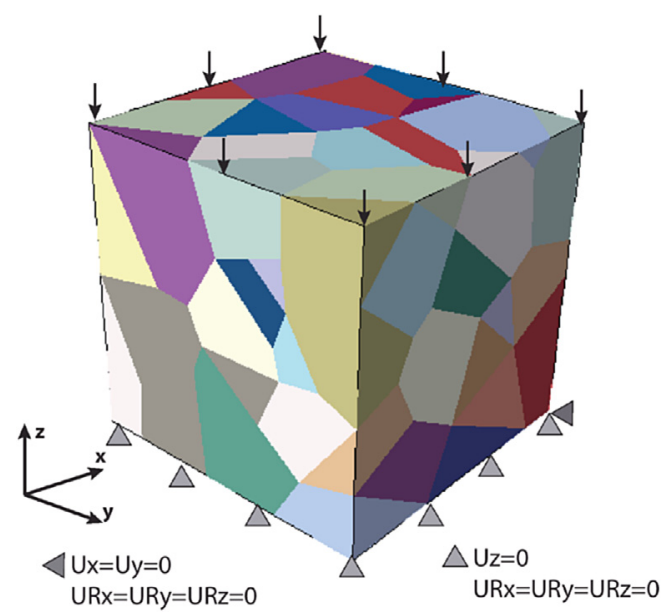

Fig. 5. The polycrystalline model. 
Table 2

Comparative study of the computing time depending on integration points number per grain and elements type.

\begin{tabular}{lllllll}
\hline & C3D4T & \multicolumn{4}{l}{ C3D8RT } \\
\hline Elements/grain & 50 & 103 & 678 & 14 & 107 & 795 \\
Computational time (min) & 30 & 41 & 350 & 6 & 87 & 1380 \\
\hline
\end{tabular}

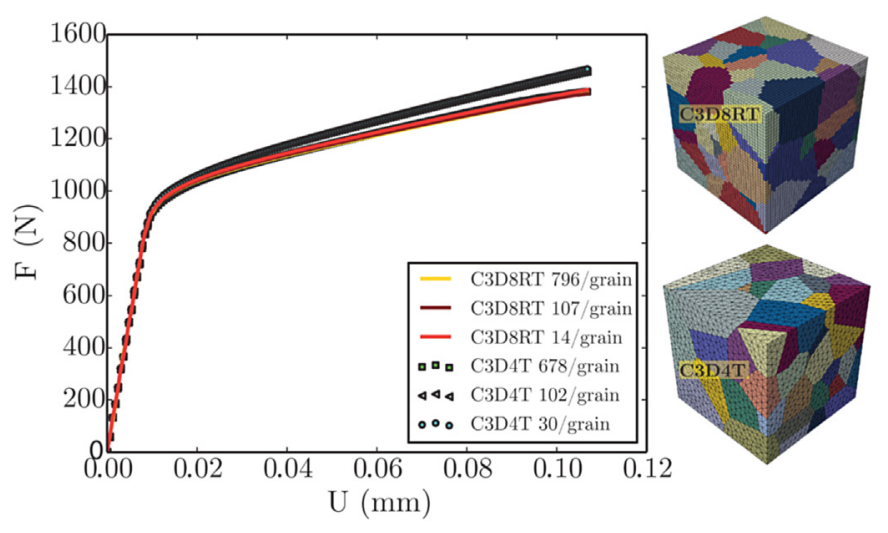

Fig. 6. Mesh convergence test $\left(\dot{\varepsilon}=10 s^{-1}\right)$.

From these equations, the evolution of associated forces variables can be determined ( $Y^{s}$ represents the damage force):

$\tau=\rho \frac{\partial \psi_{e}}{\partial \varepsilon_{e}}=\left(1-D^{T}\right) \mathcal{L} \varepsilon_{e}$

$R^{s}=\rho \frac{\partial \psi_{p}}{\partial q^{s}}=Q \sqrt{1-d^{s}} \sum_{r=1}^{N_{s}} H^{r s} \widetilde{q}^{r}$

$Y^{s}=\rho \frac{\partial \psi_{p}}{\partial d^{s}}=\frac{1}{2} \frac{\widetilde{R}^{s} \widetilde{q}^{s}}{1-d^{s}}=\frac{1}{2} \frac{R^{s} q^{s}}{1-d^{s}}$

\subsubsection{Dissipation}

The yield function and the plastic potential are defined by equations (26) and (27).

$f^{s}=\left|\widetilde{\tau}^{s}\right|+\alpha\left\langle\widetilde{\sigma}_{n}^{s}\right\rangle+\sum_{r=1}^{N_{s}} d^{r}-\widetilde{R}^{s}-\tau_{0}$

The plastic potential $\Phi^{s}$ is calculated as follows:

$\Phi^{s}=f^{s}+b q^{s} \widetilde{R}^{s}+\Phi_{d}^{s}\left(d^{s}, Y^{s}\right)$

$\tilde{\sigma}_{n}$ represents effective normal stress; $\alpha, b$ and $\tau_{0}$ are model parameters. The damage part of the plastic potential $\Phi_{d}^{s}$ is proposed by equation (28). $\beta_{d}, Y_{0}, m$ and $S$ are the damage parameters.

$\Phi_{d}^{s}=\frac{1}{\beta_{d}+1}\left\langle\frac{Y^{s}-Y_{0}}{S}\right\rangle_{+}^{\beta_{d}+1} \frac{1}{\left(1-d^{s}\right)^{m}}$

In addition to state variables, effective resolved shear stress and effective normal stress are expressed as:

$\tilde{\tau}^{s}=\frac{\tau^{s}}{\sqrt{1-d^{s}}} \quad$ and $\quad \tilde{\sigma}_{n}^{s}=\frac{\sigma_{n}^{s}}{\sqrt{1-d^{s}}}$

On the basis of plastic potential, the evolution of isotropic hardening and damage is expressed as:

$\dot{q}^{s}=-\dot{\lambda}^{s} \frac{\partial \Phi^{s}}{\partial R^{s}}=\frac{\dot{\lambda}^{s}}{\sqrt{1-d^{s}}}\left(1-\dot{\lambda}^{s} q^{s}\right)$

$\dot{d}^{s}=-\dot{\lambda}^{s} \frac{\partial \Phi^{s}}{\partial Y^{s}}=\dot{\lambda}^{s}\left\langle\frac{Y^{s}-Y_{0}}{S}\right\rangle_{+}^{\beta} \frac{1}{\left(1-d^{s}\right)^{m}}$

$\dot{\lambda}^{s}$ represents the viscoplastic multiplier. $K$ and $n$ are two parameters.

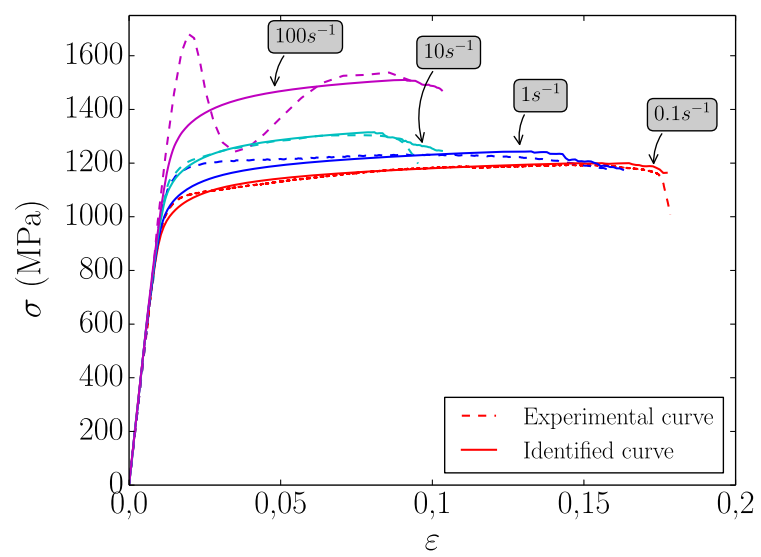

Fig. 7. $\beta$-treated Ti17 behavior at different strain rates.

$\dot{\lambda}^{s}=\left\langle\frac{f^{s}}{K}\right\rangle_{+}^{n}$

The slip rate $\dot{\gamma}^{s}$ is determined using equation (33).

$\dot{\gamma}^{s}=\dot{\lambda}^{s} \frac{\partial \Phi^{s}}{\partial \tau^{s}}=\frac{\dot{\lambda}^{s}}{\sqrt{1-d^{s}}} \operatorname{sign}\left(\tau^{s}\right)$

The plastic deformation rate at the grain level is calculated on the bases of the Schmid factor $\mu^{s}$ and it is expressed as:

$\dot{\varepsilon}_{p}=\sum_{s=1}^{N_{g}} \frac{\dot{\lambda}^{s}}{\sqrt{1-d^{s}}}\left(\operatorname{sign}\left(\tau^{s}\right) \mu^{s}+\alpha\left(m^{s} \otimes m^{s}\right) \sum_{r=1}^{N_{s}} d^{r}\right) \quad$ and

$\dot{\varepsilon}_{p}=\sum_{s=1}^{N_{g}} \dot{\gamma}^{s} \mu^{s} \quad$ for $\quad \alpha=0$

\subsubsection{Phase transition}

The modeling of phase transition for multiphase titanium alloys is a difficult task due to the complexity of the microstructure and the high dependence of the phase transformation on heating and cooling kinetics. In the case of this study, a simple model (equation (35)) was

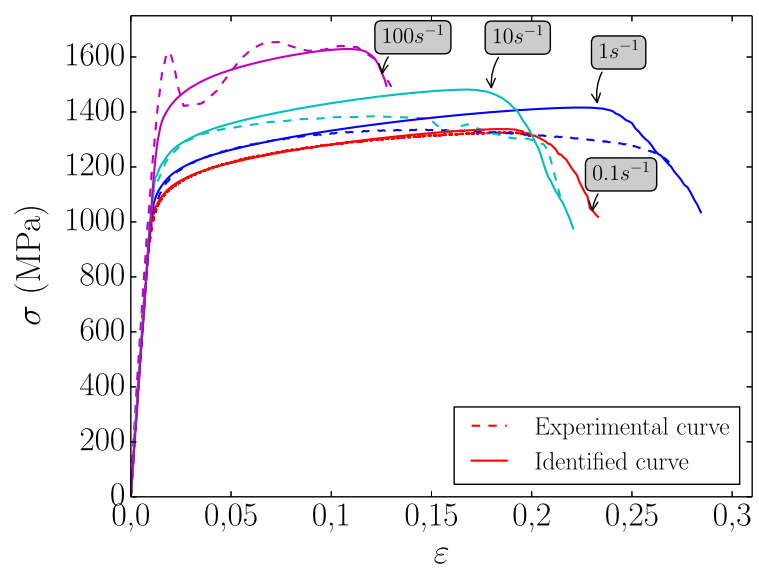

Fig. 8. Ti17 $(\alpha+\beta)$ behavior at different strain rates. 
Table 3

Material behavior law parameters for both phases at $25^{\circ} \mathrm{C}$

\begin{tabular}{|c|c|c|c|c|c|c|c|c|c|}
\hline Parameters & $K(\mathrm{MPa})$ & $n$ & $\tau_{0}(\mathrm{MPa})$ & $Q(\mathrm{MPa})$ & $b$ & $Y_{0}(\mathrm{MPa})$ & $S$ & $m$ & $\beta_{d}$ \\
\hline$\beta$ phase & 42 & 3,4 & 420 & 50 & 2 & 0 & 40 & 5 & 2 \\
\hline$\alpha$ phase & 42 & 3 & 450 & 55 & 7 & 0 & 37 & 5 & 2 \\
\hline
\end{tabular}

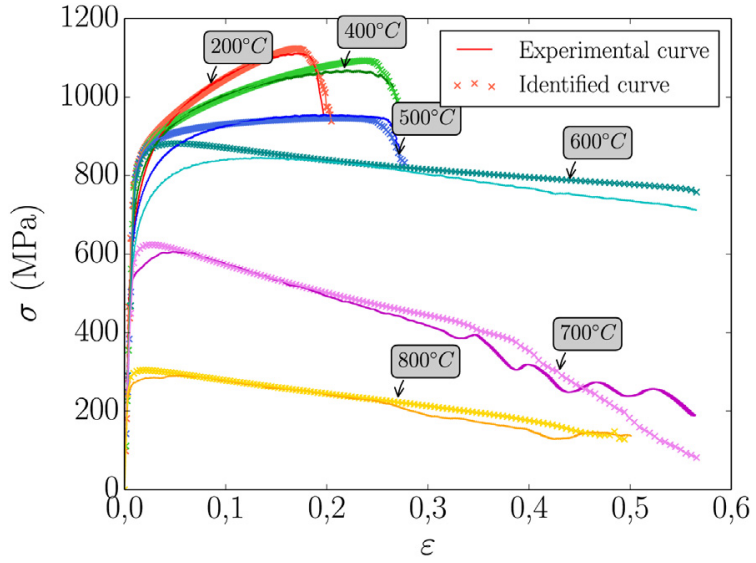

Fig. 9. Experimental and identified curves at different temperature levels.

chosen; its parameters have been identified at equilibrium by J. Teixeira [52]. It should be noted that this choice is justified by the simplicity of the model and the lack of data in the literature concerning this issue, notably at high heating and cooling rates. However, this contribution presents a step towards upgrading an already very complex cutting model.

Initially, the Ti17 Titanium alloy contains two phases ( $\alpha$ and $\beta$ ). Depending on temperature evolution, a phase transformation may occur. From a certain level of temperature, "Transus $\beta$ ", the material will be composed of only the $\beta$ phase. Equation (35) permits to calculate the $\alpha$ phase rate $\left(Z(T)_{\alpha}\right)$ in function of the temperature; with $Z_{e q}\left(20^{\circ} \mathrm{C}\right)_{\alpha}=0.67, A=0.1015$ and $T_{\beta}=880^{\circ} \mathrm{C}([52])$.

$Z(T)_{\alpha}=Z_{e q}\left(20^{\circ} \mathrm{C}\right)_{\alpha}\left(1-\exp \left(-A\left(T_{\beta}-T\right)\right)\right)$

The main calculation steps are presented in Fig. 3.

\subsection{Constitutive equation parameters identification}

Given that the Ti17 is a two-phase material, the mechanical behavior of each phase has been identified independently. Compression tests at various strain rates $\left(0.1 \mathrm{~s}^{-1}, 1 \mathrm{~s}^{-1}, 10 \mathrm{~s}^{-1}, 100 \mathrm{~s}^{-1}\right)$ and at different temperature levels (between $25^{\circ} \mathrm{C}$ and $800^{\circ} \mathrm{C}$ ) have been performed on the GLEEBLE 3500 machine. In addition, a heat treatment has been performed to carry out compression tests on specimens containing only $\beta$ phase.

The determination of the constitutive equation parameters is performed by the reverse optimization method. In this respect, the Lavenberg-Marquardt optimization algorithm has been used. This identification is performed in two stages. Initially, five hardening parameters are determined and this is followed by the identification of four damage parameters, some of which are determined for each temperature level. For each step, the identification procedure is as follows:

- Identification of $\beta$ phase parameters: these are identified on the basis of tests carried out on $\beta$ treated specimens (one phase, $\mathrm{T}=25^{\circ} \mathrm{C}$ and different strain rates levels);

- Identification of $\alpha$ phase parameters: knowing the $\beta$ phase data, $\alpha$ phase parameters are then identified (two phases, $\mathrm{T}=25^{\circ} \mathrm{C}$ and different strain rates levels);

- Identification of $\alpha+\beta$ material parameters at different temperature levels $\left(200^{\circ} \mathrm{C}, 400^{\circ} \mathrm{C}, 500^{\circ} \mathrm{C}, 600^{\circ} \mathrm{C}, 700^{\circ} \mathrm{C}\right.$ and $\left.800^{\circ} \mathrm{C}\right)$.

Fig. 4 shows the difference between the mechanical behavior of the $\beta$-treated Ti17 and the as-delivered Ti17.

The geometrical model used for the identification of the constitutive equation is presented in Fig. 5. The 100 grains constituting the model are generated and meshed using NEPER software [53]. A mesh convergence procedure has been carried out by varying the type and the number of elements per grain from 14 elements/grain to 795 elements/grain. The simulations have been carried out using multi-core parallel computing (Intel(R) Xeon(R) X5690 3.47 GHz). The obtained results are shown by Table 2 and Fig. 6 .

A better mesh convergence has been obtained with C3D8RT elements. An important integration points number per grain is required of C3D4T elements.

Crystalline orientations have been randomly assigned to each grain; the disorientation between $\alpha$ and $\beta$ phases has been taken into account ([37,54]). Since the constitutive equation does not take into account the evolution of temperature, hardening and damage parameters have been identified at each temperature level. Elasticity constants $\left(C_{i i}\right)$ also vary depending on temperature ([55]).

Figs. 7 and 8 show the results of the identification of the constitutive equation parameters for the $\beta$ and $\alpha+\beta$ phases at different strain rates. Thus, it can be seen that the material is sensitive to the strain rate, notably from $1 \mathrm{~s}^{-1}$. Similar tendencies have been obtained for both phases. It is also noted that failure strain decreases when strain rate increases. In addition, experimental trials show that fracture occurs

Table 4

Evolution of parameters depending on temperature ( $\beta$ phase).

\begin{tabular}{lllllll}
\hline$\beta$ phase & $200^{\circ} \mathrm{C}$ & $400^{\circ} \mathrm{C}$ & $500^{\circ} \mathrm{C}$ & $600^{\circ} \mathrm{C}$ & $700^{\circ} \mathrm{C}$ & $800^{\circ} \mathrm{C}$ \\
\hline$\tau_{0}(\mathrm{MPa})$ & 323.4 & 323.4 & 323.4 & 323.4 & 226.8 & 96.6 \\
$Q(\mathrm{MPa})$ & 67.5 & 44 & 10 & -16.5 & -23 & -20 \\
\hline
\end{tabular}

Table 5

Evolution of parameters depending on temperature ( $\alpha$ phase).

\begin{tabular}{lllllll}
\hline$\alpha$ phase & $200^{\circ} \mathrm{C}$ & $400^{\circ} \mathrm{C}$ & $500^{\circ} \mathrm{C}$ & $600^{\circ} \mathrm{C}$ & $700^{\circ} \mathrm{C}$ & $800^{\circ} \mathrm{C}$ \\
\hline$\tau_{0}(\mathrm{MPa})$ & 346.5 & 346.5 & 346.5 & 346.5 & 243 & 103.5 \\
$Q(\mathrm{MPa})$ & 74 & 48.4 & 11 & -18.5 & -26 & -22 \\
\hline
\end{tabular}


Table 6

Identification error estimation.

\begin{tabular}{llll}
\hline Energy $\int \sigma \varepsilon d \varepsilon\left(\mathrm{Jm}^{-3} 10^{6}\right)$ & & \\
\hline & Experimental results & Numerical simulations results & Error (\%) \\
\hline$\beta$ phase, $\varepsilon=0.1 \mathrm{~s}^{-1}$ & 197.82 & 198.53 & 0.35 \\
$\beta$ phase, $\varepsilon=10 s^{1}$ & 117.76 & 118.62 & 0.73 \\
$\alpha+\beta, \varepsilon=0.1 s^{1}$ & 264.5 & 275.5 & 4.16 \\
$\alpha+\beta, \varepsilon=10 s^{1}$ & 277.8 & 295.1 & 6.22 \\
$\alpha+\beta, 600^{\circ} \mathrm{C}$ & 438.67 & 456.13 & 3.98 \\
$\alpha+\beta, 200^{\circ} \mathrm{C}$ & 189.28 & 187.27 & 1.06 \\
\hline
\end{tabular}

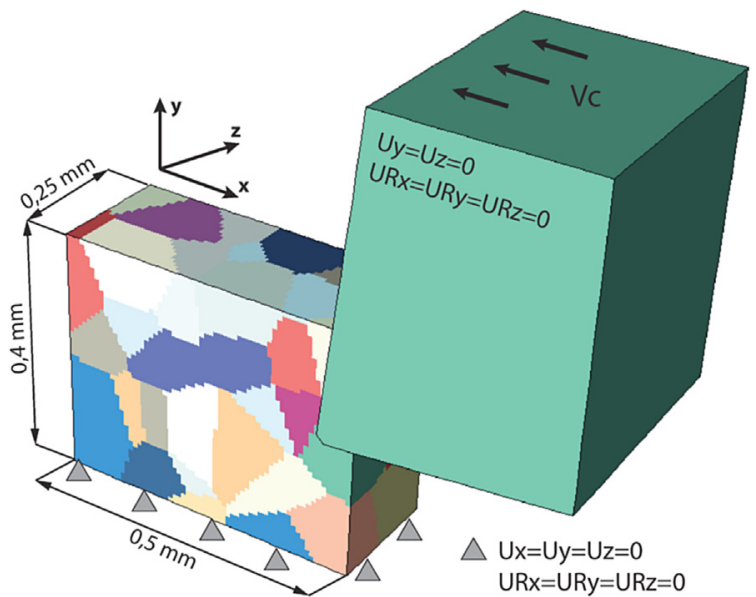

Fig. 10. Geometric model including the cutting tool and the workpiece.

more rapidly for the $\beta$ phase. The oscillations observed at $100 \mathrm{~s}^{-1}$ are mainly due to dynamic phenomena (impact tests have been carried out to reach this strain rate level).

Table 3 presents the values of the different parameters for each phase at $25^{\circ} \mathrm{C}$. Parameters $k$ and $n$ influence sensitivity to strain rate; parameters $Q$ and $b$ allow to adjust the slopes of the curves. At this stage, a proper identification of parameters $K$ and $n$ permits a good reproduction of material behavior according to strain rate. To adjust the initiation and the evolution of damage, it suffices to adjust the $S, m$ and $\beta_{d}$ parameters.

Fig. 9 shows the results of the identification of these parameters for different temperature levels. Experimental tests show that the Ti17 conserves very good mechanical properties up to $600^{\circ} \mathrm{C}$, when the thermal softening occurs. In order to identify the parameters of the constitutive equation for each temperature level, the procedure is as follows: update the $\tau_{0}$ parameter that reflects the decrease in yield for each temperature level, then calibrate the slopes of the curves, which change under the action of thermal softening, by acting on parameters $Q$ and $b$.

Tables 4 and 5, respectively, illustrate the evolution of parameters $\tau_{0}, Q$ and $S$ for the two phases.

Overall, the identified parameters make it possible to reproduce material behavior for a margin of error that does not exceed $6 \%$ as illustrated by Table 6 .

\subsection{Orthogonal cutting model}

Orthogonal cutting is a special machining configuration where the cutting edge must be perpendicular to the direction of the cutting speed $V_{c}$ and to the direction of the feed rate $V_{f}$. In this particular case of machining, workpiece width $\left(W_{w}=0.25 \mathrm{~mm}\right.$ ) becomes equivalent to the depth of cut. The cutting force is assumed to be proportional to $W_{w}$. This simplifies the understanding of physical phenomena and the examination of data. Based on the work of Ayed et al. [4], a 3D orthog-
Table 7

Thermal and mechanical properties of the tool [56].

\begin{tabular}{ll} 
Density, $\rho\left(\mathrm{Kg} / \mathrm{m}^{3}\right)$ & 12800 \\
Elastic modulus, $E(\mathrm{GPa})$ & 630 \\
Poisson's ratio, $v$ & 0.22 \\
Specific heat, $C_{p}\left(\mathrm{~J} / \mathrm{Kg}^{\circ} \mathrm{C}\right)$ & 226 \\
Thermal conductivity, $\lambda\left(\mathrm{W} / \mathrm{m}^{\circ} \mathrm{C}\right)$ & 44 \\
\hline
\end{tabular}

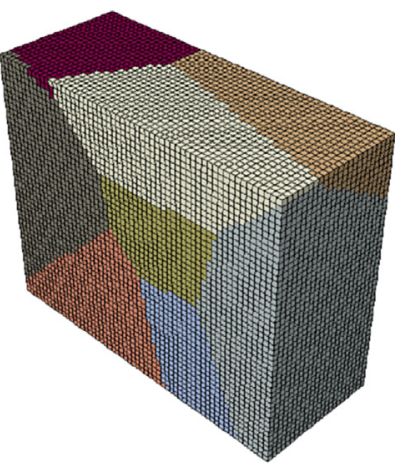

(a)

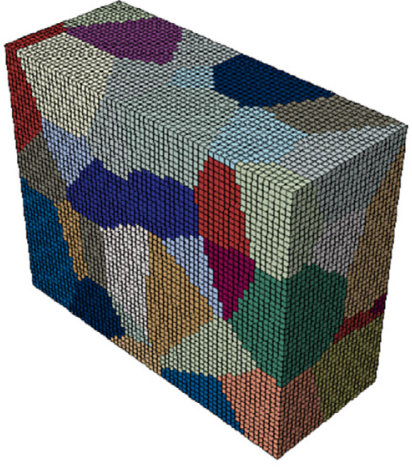

(b)
Fig. 11. Different voronoï cells mesh generation: (a) 10 grains, (b) 60 grains.

onal cutting model including a tungsten carbide tool and a Titanium (Ti17) workpiece has been established. Grains have been modeled by Voronoï cells; random orientations have been assigned to each grain. Fig. 10 renders the geometric model and illustrates boundary conditions. Table 7 presents the thermal as well as the mechanical properties of the tool.

In order to study the impact of grain number and crystallographic orientations on chip formation and cutting forces evolution, three microstructures have been generated including, respectively, 1 grain, 10 grains and 60 grains. The workpiece has been meshed with 68000 C3D8RT elements as shown in Fig. 11. Concerning the friction coefficient between the tool and the workpiece, a model taking into account the variation of the friction coefficient in function of the sliding velocity has been adopted ([56]). Previous work, carried out by Ayed et al. [4] has permitted to experimentally identify this variation (between 0.57 and 0.42 for Ti17). During chip formation, internal heating caused by plastic deformation has also been considered (The Taylor-Quinney coefficient has been set at 0.9 ). In order to simulate temperature distribution, thermal exchanges between the tool, the workpiece and the chip have taken into account. The simulations have been carried-out using ABAQUS/Explicit.

\subsubsection{Chip formation}

The main objective of this study is to develop a cutting model that allows to carry out more pertinent simulations and to access the cut- 

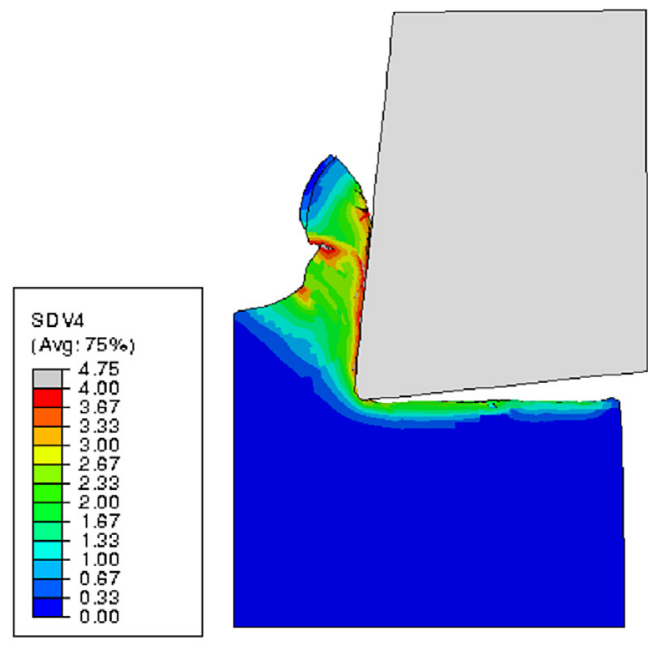

(a)

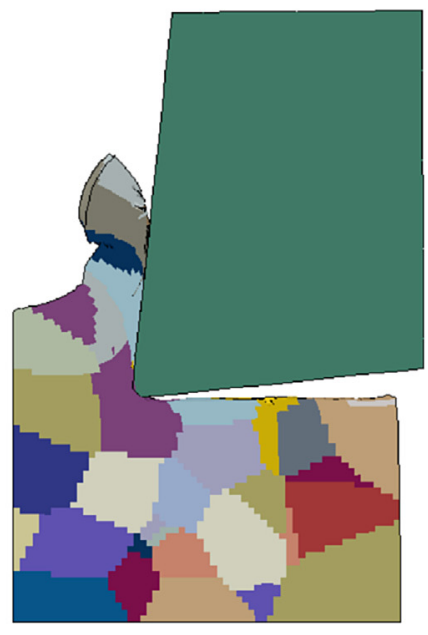

(b)

Fig. 12. Example of cutting simulation at $125 \mathrm{~m} / \mathrm{min}$ : (a) localisation of the deformation $\left(\sum \gamma_{\text {cum }}\right)$, (b) grains deformation.

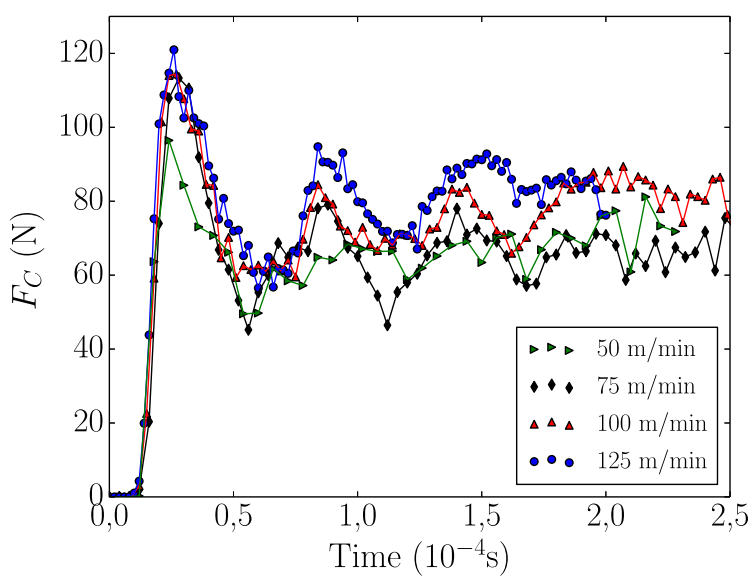

Fig. 13. Impact of cutting speed on the cutting force (numerical results).

ting area, which is otherwise experimentally inaccessible. Such a model must take into account the behavior of the material over a wide range of temperatures and strain rates, as well as the crystallographic orientations of the gains and their evolution. This is a very challenging issue due to the complexity of the cutting process. Indeed, during chip formation, the workpiece is subjected to extreme loads, and heat is generated by plastic deformation and friction at the tool/chip interface. It should be noted that damage parameters must be properly identified to ensure the separation of the chip from the workpiece.

Fig. 12 shows an example of simulation at a cutting speed of $125 \mathrm{~m} / \mathrm{min}$. As this graphic representation suggests, the grains have been highly deformed in comparison with their initial configuration (Fig. 11), notably in the chip. In addition, the figure shows the localisation of the deformation on the formed shear bands. Variable SDV4 represents the accumulated shear on all slip systems $\sum \gamma_{\text {cum }}$. The temperature reached in these areas of high deformations varies between $800^{\circ} \mathrm{C}$ and $900^{\circ} \mathrm{C}$.

\subsubsection{Impact of cutting speed and grain number}

To evidence the effects of these parameters, three cutting speeds and three grain sizes have been tested. First of all, a model including 60 grains has been set up. Then, four simulations have been carried out at different cutting speeds. The sensitivity of the cutting forces to the cutting speed is shown by Fig. 13. At the cutting speeds of $100 \mathrm{~m} / \mathrm{min}$ and $125 \mathrm{~m} / \mathrm{min}$, effort levels are close. A slight difference is observed in comparison with the effort obtained at a cutting speed of $75 \mathrm{~m} / \mathrm{min}$. Although the model takes into account the effect of heating and the degradation of mechanical properties related to temperature, the viscosity effect in the constitutive equation appears more important.

In order to verify the relevance of these simulations, orthogonal cutting tests have been carried out on a Leadwell LTC25iL CNC lathe. Cutting forces have been measured using a Kistler 9257B piezoelectric dynamometer; Fig. 14 shows the experimental setup. The average values of experimental and numerical cutting forces remain close.

The implemented constitutive equation allows, inter alia, to ensure the phase change which may occur. Fig. 15 shows the influence of the cutting speed on the evolution of the $\beta$ phase rate in the workpiece and the chip (SDV2). Increasing the cutting speed, as a matter of fact, results in an increase in the $\beta$ phase rate, especially at the tool/chip interface and the shear band. In fact, when cutting speed increases, internal heat generation due to plastic deformation also increases. The progressive temperature rise thus allows phase transition to take place. For the tested configurations, the machined surface does not undergo phase change.

In order to study the effect of grain number, two other microstructures have been generated (10 grains and 1 grain). In this step, cutting speed is set at $125 \mathrm{~m} / \mathrm{min}$. Fig. 16 shows the results of these simulations. It can be remarked that the trends and the magnitudes of the curves are close. The number of grains does not seem to have a major effect on the cutting effort; however, a slight difference is noticed with the model including a single grain.

Different simulations have been performed with different sets of orientations randomly assigned to each grain. Two grain sizes have been tested $\left(V_{c}=125 \mathrm{~m} / \mathrm{min}\right)$. Initially, three sets of orientations have been tested for a model consisting of 60 grains. Fig. 17(a) shows the results obtained. On the basis of these results, the cutting force does not seem to have been significantly influenced by grain orientations. Using a single grain model, the effects of grain orientations have then been tested. As with the previous test, Fig. 17(b) does not show significant differences in cutting force evolution. It can therefore be concluded that changing the initial random grain orientations does not considerably influence the cutting force.

Overall, these results are in agreement with experimental machining tests. Indeed, the average experimental cutting force does not undergo major changes even after repeating the same test several times. For each 


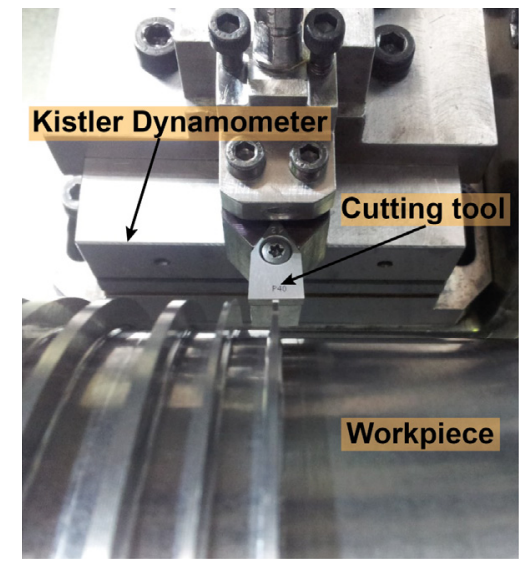

(a)

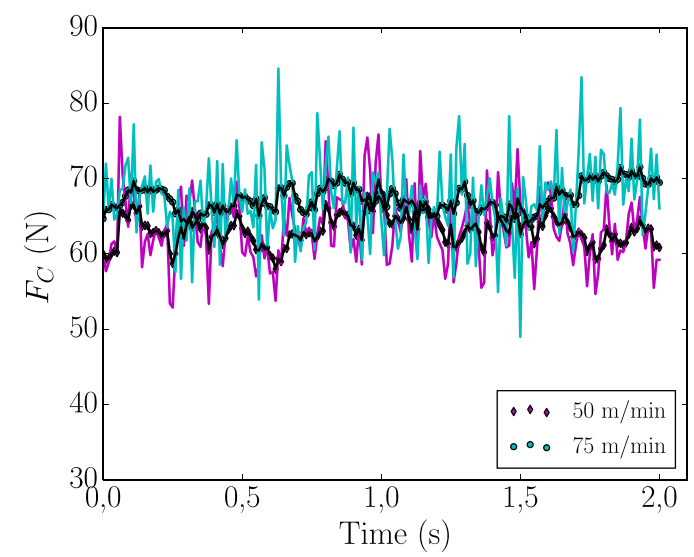

(b)

Fig. 14. Orthogonal cutting tests: (a) Experimental setup, (b) cutting forces measurement.
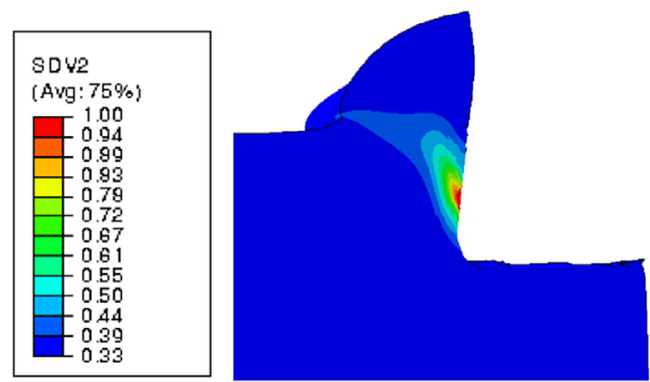

(a)

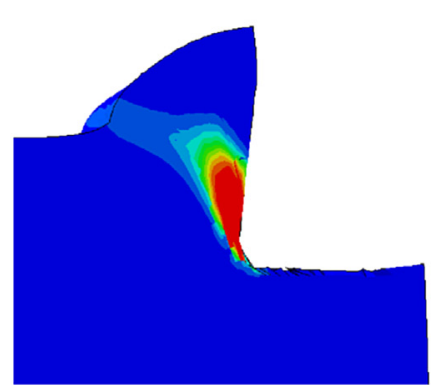

(b)

Fig. 15. $\beta$ phase rate: (a) $V_{c}=75 \mathrm{~m} / \mathrm{min}$, (b) $V_{c}=100 \mathrm{~m} / \mathrm{min}$.

test, different grains with random orientations are solicited during the cutting process, but this has no significant effect on the average cutting force.

After this phase, which is relative to the analysis of cutting forces, the geometry of the chip has been investigated. The analysis of chip formation demonstrates that the shear angle changes depending on grain orientations. Fig. 18 shows the morphology and shear angles of the chip for three sets of orientations $\left(V_{c}=125 \mathrm{~m} / \mathrm{min}\right)$. In addition, the shear angle on both sides of the workpiece is not identical and is characterized by a variation up to $17^{\circ}$ (Fig. 18(b)).

Such a change of the shear angle impacts chip morphology. Figs. 18 and 19 illustrate this variation. The localization of the deformation and its intensity likewise vary. Indeed, the accumulated shear on all slip systems SDV4 $\left(\sum \gamma_{\text {cum }}\right)$, shows a heterogeneous distribution of the deformation along the chip, which changes from one orientation to another.

Another advantage of the present model is the possibility to simulate the evolution of crystalline orientations under the action of various loads. Monitoring the evolution of textures has been done for the workpiece as well as for the chip. Figs. 20 and 21 show the evolution of texture during the machining of a workpiece containing 10 grains. Subjected to high deformation levels, the chip undergoes the most intense orientations evolution; by contrast, the change of orientations in the workpiece is less significant.

Because it is still impossible to follow the evolution of the material texture in real time during machining, the proposed model is a reliable tool capable of predicting the orientations evolution during machining or material forming.

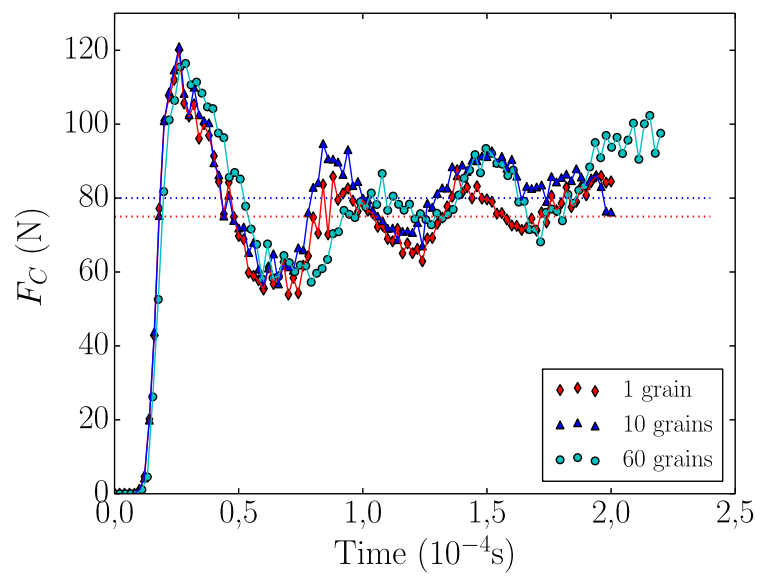

Fig. 16. Grain number influence $\left(V_{c}=125 \mathrm{~m} / \mathrm{min}\right)$.

\subsubsection{Machinability of the $\beta$ phase}

The Ti17 is known for its low machinability (high chemical reactivity, high mechanical properties and great cutting forces), which raises productivity problems (notably, the sharp increase in machining time). A heat treatment followed by the machining of the $\beta$ phase may present a potential solution to improve its machinability.

The identification of the behavior of the two phases makes it possible to simulate the machining of the $\beta$-treated Ti17 and then compare the resulting cutting forces with the as-delivered material (before heat 


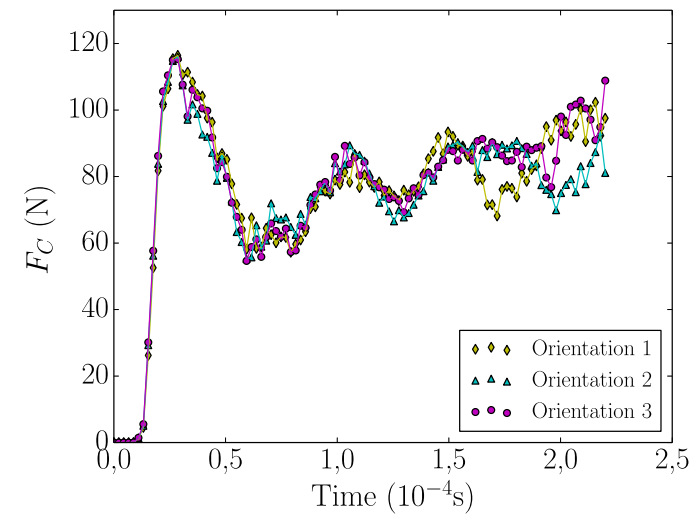

(a)

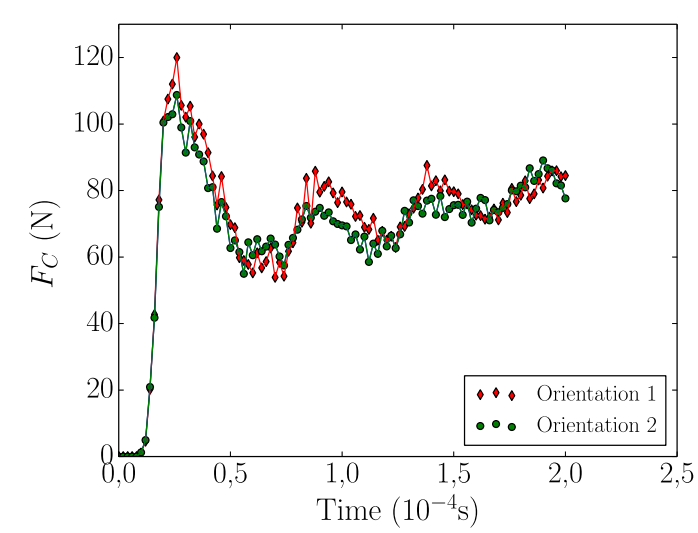

(b)

Fig. 17. Impact of crystal orientations on the cutting force: (a) 60 grains, (b) 1 grain.
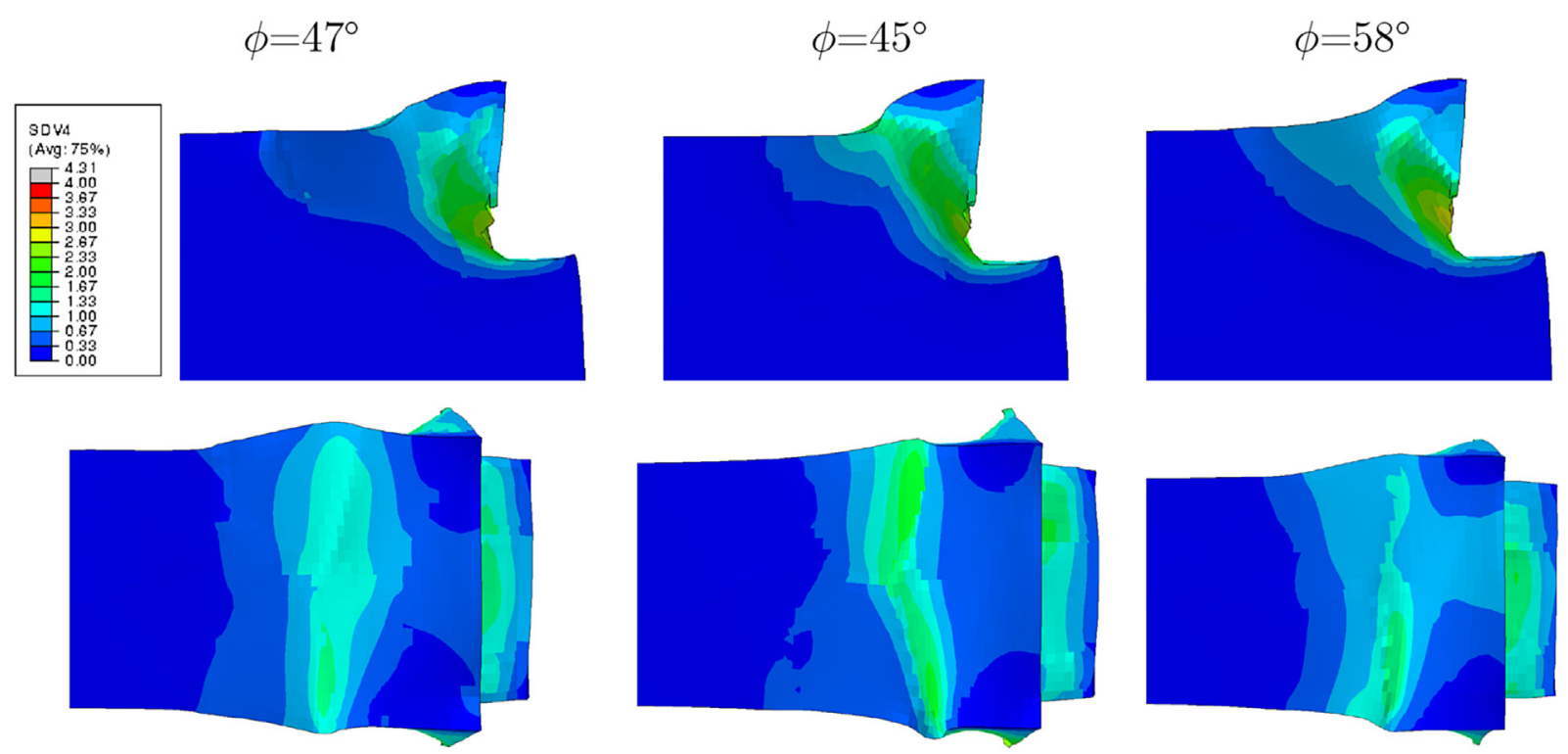

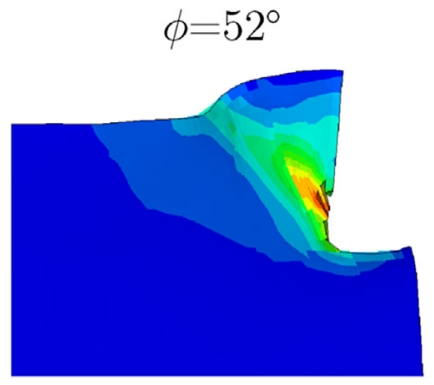

(a)

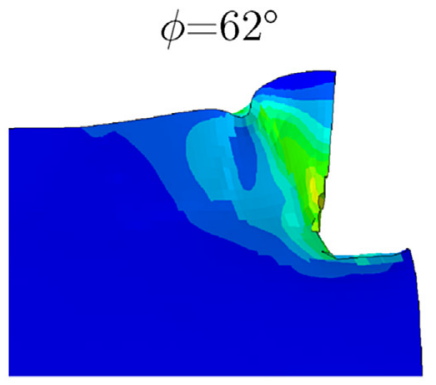

(b)

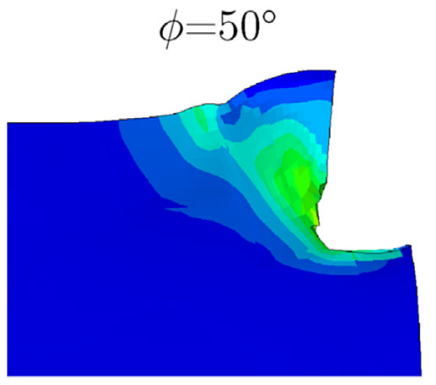

(c)

Fig. 18. Shear angle variation as a function of grain orientations: (a) orientation 1, (b) orientation 2, (c) orientation 3.

treatment). In order to carry out this simulation, two models, respectively containing 10 and 60 grains, have been established. The identified set of parameters relative to the $\beta$ phase has been used and the initial $\beta$ phase rate has been set to $100 \%$. Fig. 22 shows the results of these simulations. A decrease in cutting force ranging from $13 \%$ to $17 \%$ can thus be observed.

To confirm these numerical results, experimental tests of machining (milling) have been carried out. First, a series of machining operations has been performed on the as-delivered material. The experiment has been repeated three times. The average cutting force $F_{c}(\alpha+\beta)$ ranges from $790 \mathrm{~N}$ to $824 \mathrm{~N}$. Then, a heat treatment has been done (phase $\beta$ ) followed by a second series of tests. The average cutting force $F_{c}(\beta)$ varies from $650 \mathrm{~N}$ to $690 \mathrm{~N}$. A decrease between $12 \%$ and $21 \%$ is noted, which confirms the predictions of the numerical model. It can therefore be concluded that the machinability of the material is slightly improved after the heat treatment. 

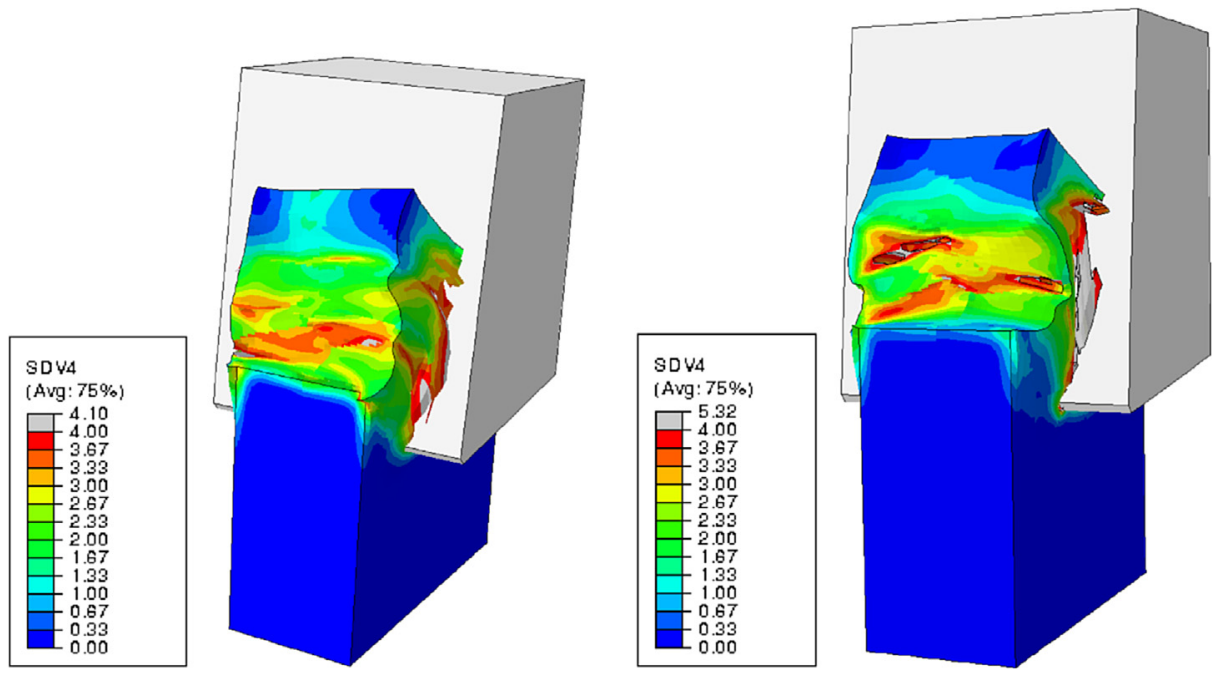

Fig. 19. Impact of grain orientations on chip morphology.
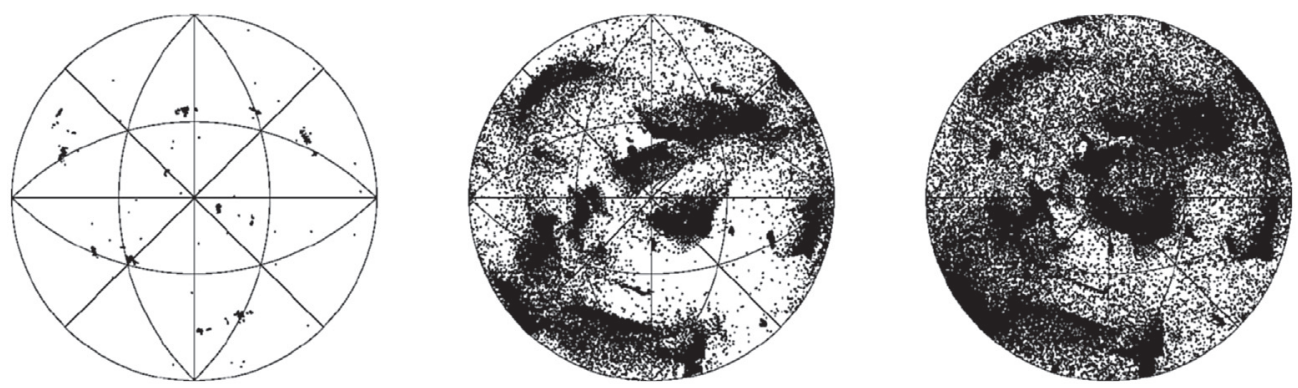

Fig. 20. Evolution of gain orientations in the chip, $\{110\}$ (10 grains).

\section{Discussion and model evaluation}

Most existing cutting models are based on the JC behavior law and damage model. This constitutive equation has the advantage of being implemented by default in most finite elements software. Indeed, it is relatively easy to identify and it permits to take into account the main material phenomena (hardening, dependence on strain rate and temperature). Although it gives good results at the macro-scale level, it has shown some limits, especially in treating metallurgical mechanisms and some physical phenomena.

The cutting model proposed in this paper is based on a micro-scale approach using a crystal plasticity constitutive equation with an explicit representation of grains (voroni cells). This approach opens up new perspectives, especially to optimize the microstructure and so enable the development of new alloys in order to improve the machinability of materials. This approach is more demanding than previous ones because it requires a more complex identification procedure for the different phases of the material. However, it allows for a more thorough study of chip formation and the stresses undergone by the surface of the workpiece which impact surface integrity (residual stress). This approach at the microstructural scale can eventually be compared to local observations in the tool tip [57] using the virtual fields method.

The first scientific challenge that was faced by this study was to implement the crystal plasticity constitutive equation while taking into account the large deformations, gain orientations evolution and phase transformation. However, it seems appropriate to continue developing the model, especially with the consideration of more accurate relations for the interaction between the different slip systems. In addition, it would certainly be rewarding to add a more accurate modeling of the behavior of grain boundaries. The first results of the machining simulations are very promising. Indeed, they demonstrate that grain size and orientations have no significant influence on the cutting force. At the level of the most solicited areas, material texture undergoes significant
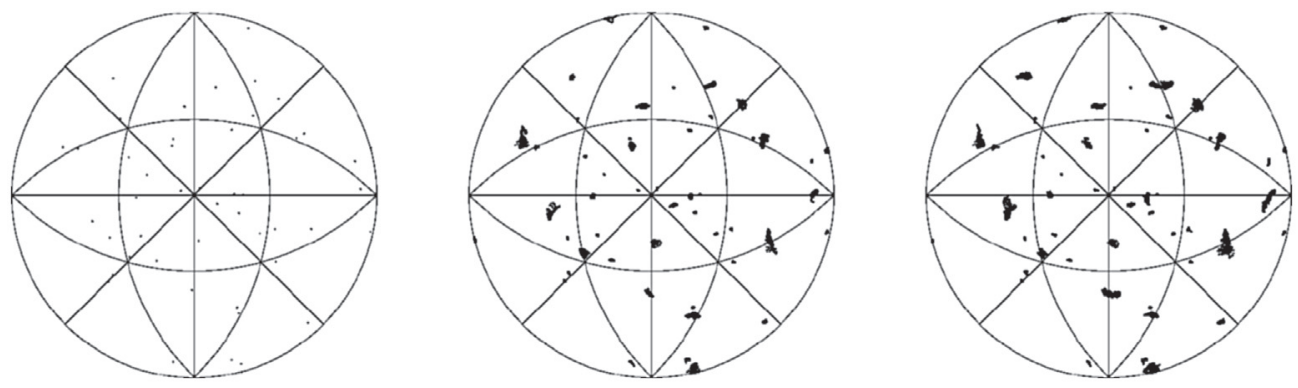

Fig. 21. Evolution of gain orientations in the workpiece, $\{110\}$ (10 grains). 


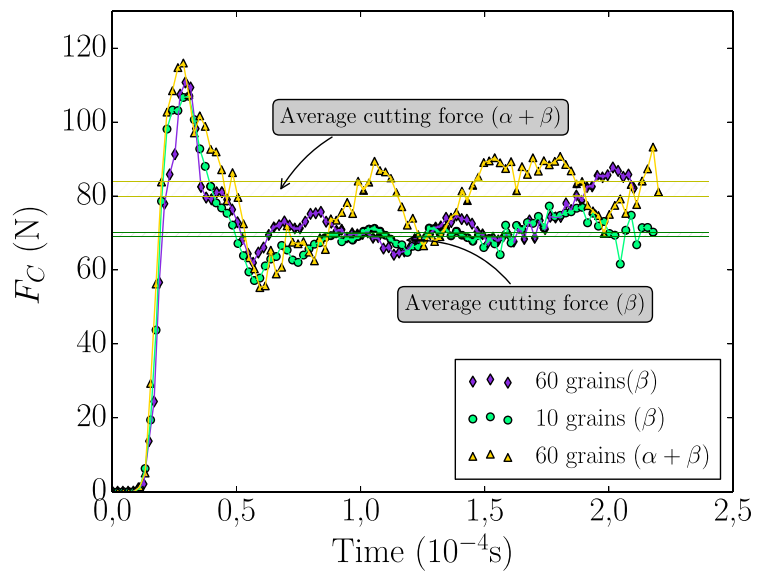

Fig. 22. Cutting force evolution during orthogonal cutting simulation of the $\beta$-treated Ti17 and the $\alpha+\beta$ Ti17

evolutions.

The second scientific challenge met was to identify the behavior of the different phases of the material and to investigate their impact on the machining of the Ti17. It has been evidenced in this respect that the machining of the $\beta$ phase results in a lower cutting force. Indeed, the rate and the inhomogeneity of the distribution of the phases in the microstructure of the material may be taken into account with the proposed model. It should be noted that the phase transition model could be significantly improved. The constitutive equation should also be modified to take into account more physical phenomena.

The proposed approach thus opens numerous perspectives for identifying thermo-mechanical loads in the tool tip and for material optimization. Indeed, this model presents venues to investigate the impact of grain size and orientations as well as phase transformation on the machinability of materials, which presents an important tool for the development of new materials.

\section{Conclusion and perspectives}

The present study has allowed the implementation of a crystal plasticity behavior law which takes into account large deformations and crystal orientations evolution. In addition, the behavior of the two phases present in the material has been identified on the basis of the reverse method. Certain parameters of this constitutive equation have also been identified at different temperature levels. An innovative 3D orthogonal cutting model has been established. This has allowed the simulation of chip formation, phase transformation $(\alpha \rightarrow \beta)$, texture evolution and cutting forces.

The impacts of grain number and orientations on the cutting force have further been studied. The results did not show a significant influence of grain size or crystal orientations on the global response of the material, especially the cutting force. Nevertheless, due to grain orientations evolution, the texture of the material undergoes significant changes. Combined with the use of a crystal plasticity constitutive equation, the explicit modeling of grains by voroni cells has enabled us to reach promising results. In addition, the developed model presents an approach which compliments Zhang's work [37].

However, there are still issues that require development. Indeed, the interaction between slip systems could improve model predictions; it would therefore be interesting to identify the interactions between the 36 slip systems. Of course, the current model can be further improved by the integration of the behavior of grain boundaries and by taking into account the effects of thermal softening.

\section{References}

[1] E. Ezugwu, Z. Wang, Titanium alloys and their machinability-a review, J. Mater Process. Technol. 68 (3) (1997) 262-274.

[2] A. Jawaid, C. Che-Haron, A. Abdullah, Tool wear characteristics in turning of titanium alloy ti-6246, J. Mater. Process. Technol. 92âĂS93 (1999) 329-334.

[3] M. Yaich, Y. Ayed, Z. Bouaziz, G. Germain, Numerical analysis of constitutive coefficients effects on fe simulation of the $2 \mathrm{~d}$ orthogonal cutting process: application to the ti6al4v, Int. J. Adv. Manuf. Technol. (2016) 1-21.

[4] Y. Ayed, C. Robert, G. Germain, A. Ammar, Development of a numerical model for the understanding of the chip formation in high-pressure water-jet assisted machining, Finite Elem. Anal. Des. 108 (2016) 1-8.

[5] S. Caruso, S. Imbrogno, G. Rotella, M.I. Ciaran, P.J. Arrazola, L. Filice, D. Umbrello, Numerical simulation of surface modification during machining of nickel-based superalloy, Procedia CIRP 31 (2015) 130-135. 15th CIRP Conference on Modelling of Machining Operations (15th CMMO).

[6] L.-E. Lindgren, A. Svoboda, D. Wedberg, M. Lundblad, Towards predictive simulations of machining, Comptes Rendus MÃI'canique 344 (4âĂŞ5) (2016) 284-295 (Computational simulation of manufacturing processes).

[7] J.C. Garcia-Gonzalez, W. Moscoso-Kingsley, V. Madhavan, Tool rake face temperature distribution when machining ti6al4v and inconel 718, Procedia Manuf. 5 (2016) 1369-1381. 44th North American Manufacturing Research Conference, NAMRC 44, June 27-July 1, 2016, Blacksburg, Virginia, United States.

[8] Q. Wang, Z. Liu, D. Yang, A.U.H. Mohsan, Metallurgical-based prediction of stress-temperature induced rapid heating and cooling phase transformations for high speed machining ti-6al-4v alloy, Mater. Des. 119 (2017) 208-218.

[9] P.-J. Arrazola, P. Aristimuno, D. Soler, T. Childs, Metal cutting experiments and modelling for improved determination of chip/tool contact temperature by infrared thermography, CIRP Ann. - Manuf. Technol. 64 (1) (2015) 57-60.

[10] J. Outeiro, S. Campocasso, L. Denguir, G. Fromentin, V. Vignal, G. Poulachon, Experimental and numerical assessment of subsurface plastic deformation induced by ofhc copper machining, CIRP Ann. - Manuf. Technol. 64 (1) (2015) 53-56.

[11] G. Johnson and W. Cook, "A constitutive model and data for metals subjected to large strains, high strain rates and temperature," in: 7th International Symposium on Ballistics, 1983.

[12] A. Simoneau, E. Ng, M. Elbestawi, Chip formation during microscale cutting of a medium carbon steel, Int. J. Mach. Tools Manuf. 46 (5) (2006) 467-481.

[13] A. Simoneau, E. Ng, M. Elbestawi, Grain size and orientation effects when microcutting aisi 1045 steel, CIRP Ann. - Manuf. Technol. 56 (1) (2007) 57-60.

[14] A. Simoneau, E. Ng, M. Elbestawi, Modeling the effects of microstructure in metal cutting, Int. J. Mach. Tools Manuf. 47 (2) (2007) 368-375.

[15] T. Obikawa, Y. Takemura, Y. Akiyama, J. Shinozuka, H. Sasahara, Microscopic phase-dependent residual stresses in the machined surface layer of two-phase alloy, J. Mater. Process. Technol. 209 (9) (2009) 4496-4501.

[16] W. Mohammed, E. Ng, M. Elbestawi, Modeling the effect of the microstructure of compacted graphite iron on chip formation, Int. J. Mach. Tools Manuf. 51 (10-11) (2011) 753-765.

[17] W. Mohammed, E. Ng, M. Elbestawi, Modeling the effect of compacted graphite iron microstructure on cutting forces and tool wear, CIRP J. Manuf. Sci. Technol. 5 (2) (2012) 87-101.

[18] H. Ding, N. Shen, Y.C. Shin, Modeling of grain refinement in aluminum and copper subjected to cutting, Comput. Mater. Sci. 50 (10) (2011) 3016-3025.

[19] R. Liu, M. Salahshoor, S. Melkote, T. Marusich, A unified material model including dislocation drag and its application to simulation of orthogonal cutting of ofhc copper, J. Mater. Process. Technol. 216 (2015) 328-338.

[20] P. Fernandez-Zelaia, S. Melkote, T. Marusich, S. Usui, A microstructure sensitive grain boundary sliding and slip based constitutive model for machining of ti-6al-4v, Mech. Mater. 109 (2017) 67-81.

[21] D. Peirce, R. Asaro, A. Needleman, Material rate dependence and localized deformation in crystalline solids, Acta Metall. 31 (12) (1983) 1951-1976.

[22] R.J. Asaro, Micromechanics of Crystals and Polycrystals, vol. 23, 1983, pp. 1-115.

[23] R. Asaro, A. Needleman, Texture development and strain hardening in rate dependent polycrystals, Acta Metall. 33 (6) (1985) 923-953.

[24] E. Schmidt, Uber die schubverfestigung von einkristallen bei plastischer deformation, Z. Fur Phys. 40 (1931) 54-60.

[25] M. Boudifa, K. Saanouni, J.-L. Chaboche, A micromechanical model for inelastic ductile damage prediction in polycrystalline metals for metal forming, Int. J. Mech. Sci. 51 (6) (2009) 453-464.

[26] X. Geng, B. Wang, Y. Zhang, J. Huang, M. Duan, K. Zhang, Effect of crystalline anisotropy and forming conditions on thinning and rupturing in deep drawing of copper single crystal, J. Mater. Process. Technol. 213 (4) (2013) 574-580.

[27] H. Zhang, X. Dong, Physically based crystal plasticity fem including geometrically necessary dislocations: numerical implementation and applications in micro-forming, Comput. Mater. Sci. 110 (2015) 308-320.

[28] A. Siddiq, T.E. Sayed, A thermomechanical crystal plasticity constitutive model for ultrasonic consolidation, Comput. Mater. Sci. 51 (1) (2012) 241-251.

[29] H. Ming Zhang, X. Huai Dong, Q. Wang, H. Zong Li, Micro-bending of metallic crystalline foils by non-local dislocation density based crystal plasticity finite element model, Trans. Nonferrous Metals Soc. China 23 (11) (2013) 3362-3371.

[30] M. Kraska, M. Doig, D. Tikhomirov, D. Raabe, F. Roters, Virtual material testing for stamping simulations based on polycrystal plasticity, Comput. Mater. Sci. 46 (2) (2009) 383-392 . 
[31] E. Cyr, M. Mohammadi, A. Brahme, R.K. Mishra, K. Inal, Modeling the formability of aluminum alloys at elevated temperatures using a new thermo-elasto-viscoplastic crystal plasticity framework, Int. J. Mech. Sci. 128 âĂS129 (2017) 312-325.

[32] J. Kadkhodapour, A. Butz, S. Ziaei-Rad, S. Schmauder, A micro mechanical study on failure initiation of dual phase steels under tension using single crystal plasticity model, Int. J. Plast. 27 (7) (2011) 1103-1125.

[33] W. Woo, V. Em, E.-Y. Kim, S. Han, Y. Han, S.-H. Choi, Stress-strain relationship between ferrite and martensite in a dual-phase steel studied by in situ neutron diffraction and crystal plasticity theories, Acta Mater. 60 (20) (2012) 6972-6981.

[34] C. Jeong, W. Woo, J. Choi, S.-H. Choi, Effect of kinematic stability of initial orientation on deformation heterogeneity and ductile failure in duplex stainless steel during uniaxial tension, Acta Mater. 67 (2014) 21-31.

[35] Gerday, Mechanical Behavior of Ti-5553 Alloy. Modeling of Representative Cells, $\mathrm{PhD}$ thesis, Université de Liége, 2009.

[36] T. Bin, X. Shao, L. Yi, H. Fengbo, K. Hongchao, L. Jinshan, Crystal plasticity finite element study of incompatible deformation behavior in two phase microstructure in near Îš titanium alloy, Rare Metal Mater. Eng. 44 (3) (2015) 532-537.

[37] H. Zhang, X. Dong, Q. Wang, Z. Zeng, An effective semi-implicit integration scheme for rate dependent crystal plasticity using explicit finite element codes, Comput. Mater. Sci. 54 (2012) 208-218.

[38] S.A. Zahedi, M. Demiral, A. Roy, V.V. Silberschmidt, Fesph modelling of orthogonal micro-machining of f.c.c. single crystal, Comput. Mater. Sci. 78 (2013) 104-109.

[39] M. Demiral, A. Roy, T.E. Sayed, V.V. Silberschmidt, Numerical modelling of micro-machining of f.c.c. single crystal: influence of strain gradients, Comput. Mater. Sci. 94 (2014) 273-278. IWCMM23 Special Issue.

[40] S. Tajalli, M. Movahhedy, J. Akbari, Simulation of orthogonal micro-cutting of fcc materials based on rate-dependent crystal plasticity finite element model, Comput. Mater. Sci. 86 (2014) 79-87.

[41] A. Li, J. Pang, J. Zhao, J. Zang, F. Wang, Fem-simulation of machining induced surface plastic deformation and microstructural texture evolution of ti-6al-4v alloy, Int. J. Mech. Sci. 123 (2017) 214-223.

[42] R. Boyer, An overview on the use of titanium in the aerospace industry, Mater. Sci. Eng. A 213 (1) (1996) 103-114.

[43] J. Mayeur, D. McDowell, A three-dimensional crystal plasticity model for duplex ti-6al-4v, Int. J. Plast. 23 (9) (2007) 1457-1485.

[44] H. Li, C. Wu, H. Yang, Crystal plasticity modeling of the dynamic recrystallization of two-phase titanium alloys during isothermal processing, Int. J. Plast. 51 (2013) $271-291$.
[45] A. Beaudoin, K. Mathur, P. Dawson, G. Johnson, Three-dimensional deformation process simulation with explicit use of polycrystal plasticity models, Int. J. Plast. 9 (7) (1993) 833-860.

[46] L. Anand, M. Kothari, A computational procedure for rate-independent crystal plasticity, J. Mech. Phys. Solids 44 (4) (1996) 525-558.

[47] M. Zecevic, R.J. McCabe, M. Knezevic, A new implementation of the spectral crystal plasticity framework in implicit finite elements, Mech. Mater. 84 (2015) 114-126.

[48] S. Dumoulin, O. Hopperstad, T. Berstad, Investigation of integration algorithms for rate-dependent crystal plasticity using explicit finite element codes, Comput. Mater. Sci. 46 (4) (2009) 785-799.

[49] H. Li, H. Yang, An efficient parallel-operational explicit algorithm for taylor - type model of rate dependent crystal plasticity, Comput. Mater. Sci. 54 (2012) 255-265.

[50] M. Rashid, S. Nemat-Nasser, A constitutive algorithm for rate-dependent crystal plasticity, Comput. Methods Appl. Mech. Eng. 94 (2) (1992) 201-228.

[51] F. Harewood, P. McHugh, Comparison of the implicit and explicit finite element methods using crystal plasticity, Comput. Mater. Sci. 39 (2) (2007) 481-494.

[52] J. Teixeira, Etude expérimentale et modélisation des évolutions microstructurales au cours des traitements thermiques post forgeage dans l'alliage de titane Ti17, $\mathrm{PhD}$ thesis, Institut National Polytechnique de Lorraine, 2005.

[53] R. Quey, P. Dawson, F. Barbe, Large-scale 3d random polycrystals for the finite element method: generation, meshing and remeshing, Comput. Methods Appl. Mech. Eng. 200 (17-20) (2011) 1729-1745.

[54] G. Martin, Numerical Multiscale Simulation of the Mechanical Behavior of Beta-metastable Titanium Alloys Ti5553 and Ti17, PhD thesis, École nationale supérieure des Mines de Paris, 2012.

[55] H. Ogi, S. Kai, H. Ledbetter, R. Tarumi, M. Hirao, K. Takashima, Titanium's high-temperature elastic constants through the hcp-bcc phase transformation, Acta Mater. 52 (7) (2004) 2075-2080.

[56] J. Rech, C. Claudin, E. D'Eramo, Identification of a friction model-application to the context of dry cutting of an aisi 1045 annealed steel with a tin-coated carbide tool, Tribol. Int. 42 (5) (2009) 738-744.

[57] T. Pottier, G. Germain, M. Calamaz, A. Morel, D. Coupard, Sub-millimeter measurement of finite strains at cutting tool tip vicinity, Exp. Mech. 54 (6) (2014) 1031-1042. 